\title{
Development of school sports facilities resources for social sharing model
}

\author{
Yingdong Song \\ Jingdezhen Ceramic Institute \\ Jingdezhen,Jiangxi,333403 China
}

\begin{abstract}
Through literature, questionnaires, interviews and other methods, we investigated the status of school gyms opening up and analyzed school resources and social sharing stadiums effects and causes. The results show: the opening stadiums mainly based on outdoor venues; the opening time of project are quite different with the masses requirements; the lack of school management and the fear of affecting the teaching force are major factors restricting the opening of school stadiums resources; mass sports organizational and management issues still need further training to solve the problem; further research on policies and measures of Public Sports Resources and more propaganda are recommended; the construction and integration of urban stadiums resources should be accelerated, to realize the balance of regional sports resources in development progressively; public interest or profitable public sports and cultural services should be supported and nurtured vigorously, and they should undertake school gyms opening up management tasks.
\end{abstract}

Keywords- Stadiums, sharing model, the research of development

\section{INTRODUCTION}

School stadiums resources and social sharing refers to school stadiums resources open to outside world and serve the community as a type of special public material resources in ensuring normal development of school sports case. School stadiums resources and social sharing will help improve the efficiency of resource use, and thus play a greater economic and social benefit. To promote school sports stadiums Resources to open to the public Scientifically and orderly, in August 2006, the State Sports General Administration and the Ministry of Education held a work conference in Shanghai to open a pilot area of national school sports venues to society, and issued the notice of Opening National School Sports Venues Pilot To the Public Work Program.

\section{MODEL THEORY}

Mode (Pattern) is the abstraction and sublimation of predecessors' experience on how to solve certain types of problems that occur repeatedly. The fundamental purpose of application mode is to improve the constantly recurring problem solving efficiency. Since the model theory is related to a certain type of problem solving methodology, so mode researches are always full of academic enthusiasm. Only in terms of sports circles, we found a large number of research results on modes by retrieving Chinese HowNet. For example, New Models Of Community Sports Development -School District Sports, research group led by ShenJianhua(1999), conducted a in-depth study on sports for the school district. Another example is GaoXueming(2007), Theory And Practice of Whole Brain Physical Education Model for Mentally Retarded Students, conducted in-depth theoretical and empirical research on the Whole Brain Physical Education Model. In terms of the application of pattern theory, sport academia mainly research on development model, centering on the development of sports.

For example ZhongJianwei, QiuJun (2006), The Digestion and Reconstruction of New Chinese Urban Mass Sports Development Model, considered that: there are three main factors influenced mass sports development pattern of the city, thus mass demand for sports, market intervention and the national administrative capital power exercise. Reconstruction of our urban mass sports development model was showing a multivariate model in the role of the three forces, including units sports mode, community sports mode and clubs mode.

Li Jianguo (2001) deeply researched on the development of community sports mode in Shanghai. The research summed up community sports development model as a theoretical framework consisted of target model, status quo mode and development mode, posing that development model is the concretization of development strategy. It is a dynamic process model transformed (transformation) from the status quo mode to target mode. With the development of society and economy, new forms sports are emerging, sports scholars have studied through model theory, anticipating the future development trend of these new sports forms and recommended the corresponding development countermeasures.

For example, YangMing (2010), research On Vacation Sports Development Model; And LiuHaiqing (2011), The Current Situation and Development Model of Coastal Sport, etc.

Thus, in order to promote the harmonious development of urban sport development, from this perspective, the use of model theory is appropriate and reasonable. And for many cities have been carrying out practical activities to promote the harmonious development of sport and produced the relevant experience and methods, this study sought by model theory for these experiences and methods to form an effective model by conclusion, summarization and 
sublimation, so as to promote the harmonious development of urban sport.

\section{Status Research ON SchoOl Resource OpEnING STADIUMS}

With the introduction of national policy of the National Fitness series, school stadiums showing the gradual opening situation. College Sports stadiums have opened advantage, and the opening ratio is relatively high.

44 schools of 48 colleges in Beijing can open venues school, accounting for $91.7 \% .79 \%$ of schools in 19 Southern region colleges and universities are opening up, of which $31.6 \%$ implementation are free opening, $47.4 \%$ are paid open. However, almost all of college sports venues are open to the community in an immature state, and the opening degree is not high, which is still relatively closed. There is still a gap compared with other countries (Japan college sports venues open rate is $97.5 \%$ ), and the main department still in a wait state. The ratio of primary and secondary school sports venues opening is relatively low, and the existing stadiums can mostly meet the teaching activities. They less open to the public, even open is only limited to the university's extracurricular activities. Different schools stadiums resources show different open situation

Most of the opening projects are adequate resources basketball, volleyball and other outdoor venues, and the basic open object-oriented is our students, but also can get a good social benefits for the community. When asked open relatively stable, the majority of working days are afternoon. Due to the low level of stadium construction, paid open conditions are not sufficient, the opening-up schools will have a direct impact on teaching management and security.

Because of the various regions and levels of the school's own resources in different stadiums, their openness is also different. Under normal circumstances, the openness of universities is higher than the primary and secondary schools, openness of outdoor venues and low cost venue is higher than indoor venues and high cost of venue. The opening time and extent of compensation is still not enough. The management and business model of Colleges and universities in the open mode is relatively simple. Many project developers have not done enough and in poor business conditions, and the open rate, development projects, management have to be further improved. The reasons that factor affecting stadiums opening are stadiums condition, management, location and concepts of school leaders. Among them, the security, management and material consumption are the main issues of sports venues opening up.

Thus, the solution of open pre-school stadium issue is to establish and improve on school stadiums and open policies, regulations. Only a clear policy direction and strong legal norms and regulations can various administrative entities and government departments have a basis to collaborate with each other.

Second, we should expand government functions, and have an administrative entity to specialize the work of supervision and management of the school gyms opening. We suggest increasing the relevant policy research on school sports and community sports development in the background of building a harmonious society.

\section{ANALYSIS ON SCHOOL STADIUMS COMMISSION BUSINESS MODEL}

\section{A. 3.1 Explanation of Entrusted Operation}

Principal-agent theory is one of the most important developments of contract theory in past 30 years, the concept of a modern agency was proposed by Ross: If the two parties, where one agent on behalf of the interests of the principal party to exercise some decision-making power, the agency relationship is subsequently produced. Its central task is to study in the environment of interest conflicts and asymmetric information, how does the principal agent design the optimal contract incentives. School sports venues agency provides an effective way to open the school stadium.

\section{B. Form of School Stadiums Entrusted Operation}

Entrusting personal business type: in the principal-agent relationship, the principal and the agent are both economic men with the motive of self-interest. And the purpose of their behavior of commission or agent is to realize the maximization of their utility. In this relationship, the school stadiums entrusted to individual operators, and agents can not consciously threat public schools and social benefits as their conduct principles. They can only maximize access to maximize benefits, and thus will not be conducive to the normal development of the rational use of school gyms and fitness activities.

Entrusting institutions operating type: in this principalagent relationship, the interest of the agent is consistent with the principal in a sense. School is in order to reduce maintenance costs and to keep a rational use of the venue, while as a proxy party, institutions want to maximize the use of the stadium resources, generating maximum public effect, and promote fitness development.

Companies operating type: In this principal-agent relationship, the agent uses market-oriented operation and reasonable to form self-management of sports facilities and the ability to scroll development. It not only basically realizes and prepares the appropriate funds for construction, but also make use of facilities' social and market effects. They can conduct a variety of operations, which can take into account both social and economic benefits.

\section{RECOMMENDATIONS}

\section{A. Government promotes the social sharing work school of sports facilities resources in coordination with relevant departments}

At this stage the government's attention, involvement, and promote are the key to solving the school sports facilities opening problem. Take an example of Wuhan, in order to open 40 pilot schools, Wuhan municipal government mobilized the power of the Education Bureau, Sports Bureau,

Civil Affairs Bureau, Public Security Bureau, Finance Bureau and other five professional bureaus to coordinate and 
plan, so the total time from proposing the idea to finalizing was miraculously less than two months. Wuhan City Board of Education has been researched thoroughly, introduced the program, coordinated by the schools; Municipal Finance Bureau particularly matched one million yuan funds for experimental work; Municipal Public Security Bureau mobilized around schools police, strengthened security checks, increased security patrols; schools were actively implementing an open venue. All these have a close relationship with the vigorously promotion from each levels of local government. Thus, what the government needs to do is, first, giving support and financial policies, the second is the coordination of all forces, and the third is to purchase services.

\section{B. Strengthen propaganda and establish a new sports concept of people-oriented}

People-oriented, is to achieve comprehensive human development as the goal, to development by starting from the actual interests of the people, to promote development, and to continuously meet the people's growing material and cultural needs, and effectively protect the economic, political and cultural rights of the people, so that the results of development can benefit all the people, and it is the essence and core of the scientific development concept. Therefore, under the guidance of adhering to the "people-oriented" concept, school sports should effectively change ideas, grasp the new requirements from the new development stage to school management and public service work, put more effort and public resources to the public Service, so as to promote comprehensive, coordinated and sustainable school sports development. The opening of school sports venues to the community brings certain problems of school management, security, economic and so on, so the school's point of view is not willing to open. But as the ideological level school leaders should stand a greater level of national, social and ethnic groups to consider this question, thus sacrificing the material self, offering the greater self.

\section{Sound system for standardized management}

Establish a new system is the basis of any management work, the escalation of long-term mechanism of school sports facilities opening work must through the appropriate regulations. For a comprehensive opening of school sports facilities to the public, in terms of the management system, we recommended the establishment of the school sports facilities Ministry of Manpower Resources and Social sharing, which is led by the municipal government. City Board of Education, Sports Bureau, Civil Affairs Bureau, Public Security Bureau, Finance Bureau and other relevant sectors should be coordinated to develop school sports facilities social sharing implementation measures, which should be supported with a series of related policies, such as the principle of openness, security conditions, the corresponding provisions of the management system and operation mechanism, as well as the responsibilities of the parties, rights and interests. Use the system to guarantee the opening work of school sports facilities to the public.

\section{Establish security mechanisms to achieve risk-sharing from multiple aspects}

For issues those may occur during opening process such as personal safety and schools property security, insurance system should be established consisted of insurance system, emergency response mechanisms and public security inspection system, with multifaceted combination, comprehensively protect the normal and orderly openness of school stadiums. The first is purchase insurance and transfer risk.

Currently, CSIB and Pacific Insurance Co., Ltd. and others have provided special liability insurance for school sports venues to open to the public. Its advantage is to provide compensation according to the school legal liability in an accident. What's more, you can follow the results of the litigation or arbitration, also can compensate in consultation between school and the parties with the agreement of insurance company. Therefore, this program is in case of the risk of an accident and makes full preparations to deal with the economy, using reasonable means and costs to high liability risk, to a certain extent for the school to solve the worries.

The secondly is the establishment of emergency mechanisms. Schools should develop an emergency evacuation measures and mechanisms to deal with all types of emergencies personnel and disasters, and posted in conspicuous places, so that the majority of students and exercisers in school gym were aware of approaches to natural disaster or unexpected event. Thirdly, public security inspection system should be established, which must in close contact with the area of the police station, and actively cooperated with the local public security organs. We should implement social security comprehensive management leadership responsibility, target management responsibility, liaison system, inspection system, etc., so as to form a security force.

\section{CONCLUSION}

The openness of school stadiums resources to the community is an important part of China's social development and progress, which will play an essential role for building a socialist harmonious society. Strengthen research work on school stadiums open to social issues is one important part to promote school sports facilities resources open to society. Because of vast regional differences, there appear of significant economic and social development imbalance between urban and rural development.

Also because the hierarchy of school stadium construction on the school level, as well as the economic, educational, legal, social and other issues related to opening up more areas, it determines the complexity. Some weak areas, weak issues such as policy researches, study on rural issues, the integration researches and other sports school community researches should be accelerated. 


\section{REFERENCES}

[1] Cheng Yunhong. Research On School Stadiums Social Resources Sharing Mechanism and Mode [D]. Ningbo University, 2009.

[2] Zhang Lixin, Liu Chonglei. Research On Universities and Colleges Social Resources Sharing Model Stadiums Building - A Case Study of Tianjing City [J] Movement, 2010,09: 150-151.

[3] XuSuodi,ZhouTong. Researches On the Social Share of School Sports Facilities Resources in Ningbo City [J] Zhejiang Sport Science, 2010,06: 29-32.
[4] Qishu Chun. Urban Sports Development Under Harmonious Society Construction [D]. Shanghai Institute of Physical Education, 2011.

[5] Wang Zhe, Liang Hongxia, Shusheng Fang. Sharing Resources And Social Status Quo Stadiums Pilot Schools in Shanghai [J] Sports Research, 2011,06: 88-91. 